\title{
Innovation in Collaboration \\ The Summer Institute on Youth Mentoring as a university-community partnership
}

\author{
Kevin R. Jones \\ Thomas E. Keller
}

Portland State University
Marc Wheeler

Big Brothers Big Sisters of America
Gateways: International Journal of Community Research and Engagement Vol 4 (2011): 168-85 (C) UTSePress and the authors

ISSN 1836-3393
University-community partnerships are designed to address pressing social problems by combining the goals and resources of colleges and universities with those of community stakeholders. Ideally, partnerships develop as symbiotic projects that empower community organisations, enrich the community, and provide unique sources of data for research and evaluation. Partnerships take many forms and have a wide range of goals, from promoting health, to developing sustainable neighbourhoods, to improving public education. They may involve university students serving an under-resourced area of the community, or community members entering the university to participate in dialogue, planning and research. Universities and community partners may also work together to make research findings accessible to the wider community, increasing the chances that important advancements in scientific knowledge are applied in practice. Likewise, partnerships provide a forum for professional knowledge to shape the direction of academic research. With so many variations, locations and goals - and because securing funding for partnership projects is increasingly difficult (US Department of Housing and Urban Development 2010) - it is important for partnership researchers to identify commonalities present in the most effective university-community partnership models. Researchers have recently begun to define the characteristics of successful university-community partnerships.

Following a review of recent developments in the literature, this article explores the utility and flexibility of one of the more comprehensive partnership frameworks by applying it to a distinctive university-based summer institute designed to foster the exchange of knowledge between researchers and practitioners in the field of youth mentoring. One aim of the study reported here was to evaluate whether factors typically considered important for these partnerships would translate across contexts and provide a relevant conceptualisation for the summer institute model. Another goal was to learn how partnership criteria might be 
further expanded and adapted. Based on the findings of the study, suggestions are also made for possible innovation in established university-community partnership models.

\section{PARTNERSHIP TYPES AND TRENDS}

In 1994, the US Department of Housing and Urban Development (HUD) established the Office of University Partnerships (OUP) to promote the establishment and growth of university-community partnerships nationwide. In 1999, HUD published a report that described hundreds of partnerships divided into seven main categories: service-learning, service provision, faculty involvement, student volunteerism, community in the classroom, applied research, and major institutional change. HUD's Community Outreach Partnerships Centers (COPC) program was one of the largest efforts to promote cooperation among universities and local partners, with a focus on spurring economic development and providing safe, affordable housing in urban areas. However, the Bush Administration gradually scaled back federal support for partnerships, and by 2005 the COPC program was receiving no additional funding, effectively ending many large-scale, federally funded partnership projects. Some partnerships found innovative ways to continue without federal funds (Bloomgarden et al. 2006), and another outcome was the development of new university and community college offices dedicated to supporting universitycommunity partnerships.

The current study explores a 'community in the classroom' partnership designed to bridge the often-disconnected worlds of research and practice. Service providers often find it difficult to keep up with the latest developments in research (Gira, Kessler \& Poertner 2004). In a review of randomised controlled studies of dissemination efforts in health professions, Gira, Kessler and Poertner (2004) found that distributing research findings to practitioners (without additional implementation strategies) was ineffective in changing practice behaviours. The authors also found that traditional continuing education and professional development opportunities using only didactic techniques were also ineffective, while small group discussion and practice sessions generated moderate to large effect sizes compared to the control group. Addis (2002, p. 375) argued that hierarchical and unidirectional methods of dissemination created resistance to implementation and that 'Practitioners are more likely to adopt research products when they find them useful and can contribute creatively to their development and evaluation'. Sherrod (1999, p. 234) pointed specifically to the potential of university-community partnerships, which 'play many important roles, but an especially critical one is their attention to dissemination of research findings'. These findings suggest that more collaborative, partnershiporiented dissemination processes may hold promise for improved integration of scientific knowledge into professional practice. 
Table 1: Comparison of four lists of characteristics for successful universitycommunity partnerships

\section{CHARACTERISTICS OF SUCCESSFUL PARTNERSHIPS}

An emerging body of literature has begun to define characteristics of successful collaborative efforts (Cardoza \& Salinas 2004; Mai, Kramer \& Luebbert 2005; Torres \& Schaffer 2000; Schumaker, Reed \& Woods 2000), as well as common challenges encountered by university-community partnerships (Lane, Turner \& Flores 2004). Torres and Schaffer (2000) offer a comprehensive outline of eight essential partnership features, compiled from proceedings of the 1998 Wingspread Conference on university-community partnerships. Based on their experiences with COPC, Schumaker, Reed and Woods (2000) also offer eight ingredients for successful collaboration from the university's perspective. While there are slight differences between the lists, both research teams stress the importance of having a shared vision, clear communication and a clear organisational structure. Mai, Kramer and Luebbert (2005) put forward a similar, more distilled list based on a review of over a dozen partnerships. Cardoza and Salinas (2004) narrowed their list of key components for successful partnerships to five and their findings support the conclusions of the other authors. The current study employed the eight characteristics described by Torres and Schaffer (2000) as the analytic framework because it was the most comprehensive and had significant overlap with the findings of other studies. The four lists are compiled and compared in Table 1.

\begin{tabular}{|c|c|c|c|}
\hline $\begin{array}{l}\text { Torres \& } \\
\text { Schaffer } 2000\end{array}$ & $\begin{array}{l}\text { Schumaker, } \\
\text { Reed \& Woods } \\
2000\end{array}$ & $\begin{array}{l}\text { Mai, Kramer \& } \\
\text { Luebbert } 2005\end{array}$ & $\begin{array}{l}\text { Cardoza \& } \\
\text { Salinas } 2004\end{array}$ \\
\hline & $\begin{array}{l}\text { A history of } \\
\text { collaboration }\end{array}$ & & \\
\hline \multirow{3}{*}{$\begin{array}{l}\text { Founded on a } \\
\text { shared vision and } \\
\text { clearly articulated } \\
\text { values }\end{array}$} & Shared vision & $\begin{array}{l}\text { Formulation of } \\
\text { shared objectives }\end{array}$ & Vision \\
\hline & & $\begin{array}{l}\text { Reflecting on the } \\
\text { purpose of the } \\
\text { partnership }\end{array}$ & \\
\hline & $\begin{array}{l}\text { Informality and } \\
\text { flexibility }\end{array}$ & & Flexibility \\
\hline \multicolumn{4}{|l|}{$\begin{array}{l}\text { Beneficial to } \\
\text { partnering } \\
\text { institutions }\end{array}$} \\
\hline $\begin{array}{l}\text { Composed of } \\
\text { interpersonal } \\
\text { relationships } \\
\text { based on trust } \\
\text { and respect }\end{array}$ & $\begin{array}{l}\text { Good personal } \\
\text { relationships, } \\
\text { including high } \\
\text { levels of trust }\end{array}$ & & \\
\hline
\end{tabular}




\begin{tabular}{|c|c|c|c|}
\hline $\begin{array}{l}\text { Torres \& } \\
\text { Schaffer } 2000\end{array}$ & $\begin{array}{l}\text { Schumaker, } \\
\text { Reed \& Woods } \\
2000\end{array}$ & $\begin{array}{l}\text { Mai, Kramer \& } \\
\text { Luebbert } 2005\end{array}$ & $\begin{array}{l}\text { Cardoza \& } \\
\text { Salinas } 2004\end{array}$ \\
\hline $\begin{array}{l}\text { Multi- } \\
\text { dimensional: } \\
\text { involve the } \\
\text { participation of } \\
\text { multiple sectors } \\
\text { addressing a } \\
\text { complex problem }\end{array}$ & & $\begin{array}{l}\text { Creating } \\
\text { structures } \\
\text { to support } \\
\text { collaboration }\end{array}$ & Collaboration \\
\hline $\begin{array}{l}\text { Clearly organised } \\
\text { and led with } \\
\text { dynamism }\end{array}$ & $\begin{array}{l}\text { Simple } \\
\text { organisational } \\
\text { structure }\end{array}$ & & \\
\hline $\begin{array}{l}\text { Integrated into } \\
\text { the mission and } \\
\text { support systems } \\
\text { of the partnering } \\
\text { institutions }\end{array}$ & $\begin{array}{l}\text { Linking and } \\
\text { integrating } \\
\text { with university } \\
\text { resources }\end{array}$ & & Support \\
\hline \multirow[t]{2}{*}{$\begin{array}{l}\text { Sustained by } \\
\text { a 'partnership } \\
\text { process' for } \\
\text { communication, } \\
\text { decision-making } \\
\text { and initiation of } \\
\text { change }\end{array}$} & $\begin{array}{l}\text { Clear and } \\
\text { frequent } \\
\text { communication }\end{array}$ & & Communication \\
\hline & $\begin{array}{l}\text { University's } \\
\text { visibility }\end{array}$ & & \\
\hline $\begin{array}{l}\text { Evaluated } \\
\text { regularly with } \\
\text { a focus on both } \\
\text { methods and } \\
\text { outcomes }\end{array}$ & & $\begin{array}{l}\text { Consulting data } \\
\text { to assess outcomes }\end{array}$ & \\
\hline
\end{tabular}

Common challenges of establishing and maintaining successful partnerships have also been identified (Lane, Turner $\&$ Flores 2004). Partners with an initial shared vision may find they have differing perspectives on key issues. For example, Lane, Turner and Flores (2004) described a researcher-practitioner partnership in the corrections field that encountered obstacles due to disagreements over program implementation and evaluation. Cherry and Shefner (2004) identified issues of class, status and organisational differences as common impediments to successful university-community collaboration. In addition, some researchers have suggested that the short-term nature of most funding streams may render many partnership efforts unsustainable (Baum 2000).

\section{THE SUMMER INSTITUTE ON YOUTH MENTORING}

Youth mentoring is a prevalent and popular mode of intervention with children and youth across the nation (Walker 2007). Some formal youth mentoring programs, most notably those affiliated 
with Big Brothers Big Sisters of America, have long histories and strong national networks. However, most programs are more loosely connected through organisations that provide advocacy, training and technical assistance, such as MENTOR/The National Mentoring Partnership, which currently has more than 5000 formal programs listed in its nationwide database of mentoring programs (K Zappie-Ferradino, personal communication, 11 February 2011). In most programs, service approaches have evolved gradually with the accumulated experience of practitioners. In the past 15 years, however, researchers have made a concerted effort to evaluate the effects of mentoring and to investigate the processes by which mentoring influences youth development (DuBois \& Karcher 2005). The emergence of a theoretical and empirical literature addressing important issues in youth mentoring has facilitated a productive exchange between the academic and practice communities. In fact, a selfidentifying community of practitioners with interests in research is beginning to coalesce, as reflected by 480 subscribers to the YouthMentoringListserv, a vehicle for disseminating youth mentoring research and practice knowledge (D DuBois, personal communication, 11 February 2011).

The Summer Institute on Youth Mentoring (SIYM) at Portland State University (PSU) was designed to offer a new and distinctive educational opportunity for experienced youth mentoring professionals. Participants attend an intensive weeklong seminar discussing recent developments in theory and research on youth mentoring. Each session is led by a prominent, nationally recognised research fellow. The aim is a series of highly interactive discussions that provide an in-depth view of the research and examine its implications for practice. To encourage an active exchange among professional peers and with researchers, SIYM employs a small-group format (5-6 researchers, 25-30 professionals) with a selective admissions process. Ideal participants have several years of experience in the field and are seeking advanced professional development. Participants hold positions that enable them to influence the training and supervision of staff, the development of program models and the implementation of service delivery changes. Sessions include ample time for participants to think critically about their own program issues and explore opportunities for innovation. A fundamental premise of SIYM is that dialogue between experienced professionals and researchers stimulates relevant research and enhances translation to practice. This reciprocity between researcher and practitioner reflects what Saltmarsh, Hartley and Clayton (2009, pp. 9-10) call 'an epistemological shift that values not only expert knowledge that is rational, analytic and positivist but also values a different kind of rationality that is more relational, localized, and contextual and favours mutual deference between lay persons and academics. Knowledge generation is a process of co-creation, breaking down the distinctions between knowledge producers and knowledge consumers'. 


\section{EVIDENCE FOR EFFECTIVENESS OF THE 2007 SUMMER INSTITUTE}

Created in 2007, the Summer Institute on Youth Mentoring aimed to produce mutual benefits for practitioners, researchers and the field of youth mentoring generally. An initial analysis of participant questionnaires indicated that the 2007 SIYM was largely successful in achieving its goals of providing a forum for professionals and researchers to exchange information, build relationships and plan together to improve mentoring research and programs (Jones \& Keller 2009). Specifically, findings indicated that SIYM facilitates mutually beneficial relationships between researchers and practitioners; inspires new or renewed interest in research among practitioners; facilitates new collaborations among researchers; catalyses program innovation and improvement; facilitates planning and goal-setting among practitioners; and successfully promotes professional development.

Although the 2007 Summer Institute was considered successful, several areas for improvement were identified. SIYM organisers reviewed participant feedback and made adjustments before the 2008 event. More small group activities and discussions were incorporated into the presentation sessions. Structured social time was added in the form of a networking dinner. The success of the 2007 event and a successful grant proposal to conduct further analyses prompted the authors to begin considering SIYM as a promising and innovative university-community partnership model.

\section{STUDY AIMS AND METHOD}

The current study was designed to accomplish two main goals: 1) to evaluate the 2007 Summer Institute on Youth Mentoring in terms of established criteria that characterise successful universitycommunity partnerships, and 2) to describe significant innovations introduced by SIYM that may add to current knowledge about how university-community partnerships can be most effective.

All 2007 SIYM participants were recruited to participate in the study. Consent forms were distributed with SIYM materials on the first day of the seminar, and all 24 forms were signed and returned. All five 2007 research fellows were also recruited for participation. Consent forms were distributed to research fellows via email and were returned by fax or mail.

On the last day of the seminar, questionnaires were distributed to all 24 participants. The questionnaires asked participants a series of open-ended questions about their experiences at SIYM and invited suggestions for improvement. Twelve participants (50 per cent) returned completed surveys on the last day of the seminar or by mail or email in the weeks following the event. The research fellows were asked to complete a separate questionnaire six to eight months following the 2007 Summer Institute. Four of the five researchers ( 80 per cent) returned 
completed questionnaires by email or by mail. All completed questionnaires were converted to electronic documents and entered into ATLAS.ti for analysis.

Data were analysed in three stages. The first two stages used inductive, exploratory and grounded theory methods (Strauss \& Corbin 1990) to label and synthesise questionnaire responses as they related to SIYM's overall mission. First, open coding was used to label, line by line, participant responses to the post-seminar questionnaire. The second stage consisted of axial coding, in which initial codes were grouped and organised into about a dozen main categories (e.g. participant professional development). After this stage, the initial evaluation of the Summer Institute was conducted, resulting in the findings summarised above (Jones \& Keller 2009).

The third stage of data analysis was a typological analysis (Hatch 2002), in which the coded data were re-examined and recategorised according to characteristics of successful partnerships (Torres \& Schaffer 2000). After coding and assignment of data to the typological categories based on the partnership framework, the researchers examined the contents of each category for subgroupings, trends, or differences among the responses. A final step in the typological analysis was to examine all data not fitting one of the predetermined categories, and to decide whether they represented a useful addition to the partnership model. The typological analysis, including the identified innovations, yielded the results reported below.

The subjective nature of qualitative enquiry requires that researchers establish the trustworthiness of the research process and findings to increase confidence that rigorous methods were employed and that participants' voices were heard (Lietz, Langer \& Furman 2006). The current study employed several strategies to ensure trustworthiness, including member checking, an electronic audit trail and a reliability check of the typological analysis by a researcher not involved with the study. The coding reliability check showed better than 76 per cent correspondence for assignment to categories, with discrepancies largely due to participant statements that reflected several categories simultaneously.

\section{STUDY FINDINGS}

Study participants reflected on a number of topics related to the conception of the Summer Institute on Youth Mentoring as a university-community partnership. The findings are first presented in terms of how well the data supported a correspondence between key characteristics of SIYM's success and Torres and Schaffer's (2000) criteria (see Table 1). Excerpts from questionnaire transcripts illustrating these connections are presented in the relevant sections below. Findings are then presented in terms of innovations to established partnership models apparent in SIYM. 


\section{Shared Vision}

Data supported the centrality of a shared vision among participants for program improvement through interactive and intensive information sharing. Participants' responses strongly suggested that having time away from work and other 'day-today responsibilities' was critical to the success of the SIYM format. Participants also listed dozens of specific goals and plans for program improvement they intended to pursue upon returning to work. The interactive nature of the seminar also stood out for participants as a key characteristic. Several participants stated that the intimate setting and the full week of sessions allowed a 'deep dive' into important topics that was 'very rich and valuable'. Participants also anticipated that relationships developed at the SIYM would continue and that 'Having actually met and dialogued with researchers in the field has made the research "more real" to me ... and therefore further energised my interest in staying up on the research. I have established a new network of professional friends to whom I can turn with my questions, need for support and/or information'. These elements together suggest that the original vision for SIYM stated by the founder in the first grant proposal was widely shared by participants:

SIYM is an approach for facilitating direct communication and collaboration to bridge the traditional divide between research and practice. The program leverages university resources to address an influential audience whose needs are not well met by current training programs.

\section{Mutual Benefit to Partnering Institutions}

SIYM gave participants the opportunity to build relationships and develop their own professional skills and knowledge. As one participant said: 'As I was listening to the researchers' present their studies this past week, I was constantly evaluating what they were telling us and how that could inform best practices at my agency.'

Several participants also expressed the deeply personal nature of their experiences at SIYM, with one participant writing: 'This seminar has been profoundly meaningful to me on a number of levels. I have approached the content primarily as an executive director ... but I have also responded to the content in my role as a Big Brother in a school-based mentoring program and as a father to a three-year-old daughter.'

The research fellows received valuable feedback from practitioners regarding the potential utility of their findings and what additional research would be useful. The researchers also initiated collaborations with practitioners and other researchers to pursue new research topics, develop assessment strategies and plan additional events that bring researchers and practitioners together. One researcher stated: 'I made tremendous strides on my mentorrelated writing projects and received some valuable feedback on a planned grant proposal.' 
Finally, Portland State University gained important exposure as a pioneer in facilitating collaboration between youth mentoring researchers and practitioners. Websites, articles, newsletters and book reviews mentioned the SIYM experience and the value it was adding to the field (e.g. Karcher 2008). The Dean of the PSU School of Social Work said that she believed the SIYM model would inform other efforts to bridge research and practice at the school.

\section{Development of Interpersonal Relationships}

Respondents stressed the importance of the relationships they had developed with other mentoring professionals from across the country and the world. Participants also appreciated the unique perspectives other participants presented, and one participant felt 'empowered to be part of such a prestigious group of people in the field of mentoring'.

Several participants also formed strong connections with researchers during the week and planned further communication and collaboration to address specific agency issues: 'I also feel that just getting to know these researchers and my colleagues from around the USA and Canada improves me professionally and increases the likelihood that I maintain contact with them over time.'

The researchers also developed relationships with each other and spent time discussing current projects as well as potential opportunities for collaboration. Researchers expressed a deepening of respect for practitioners and their professional knowledge and noted how they planned to collaborate with practitioners in the future.

Participants suggested that developing long-term relationships with one another could be facilitated through additional structure provided by the institute. One researcher suggested an institute newsletter to keep participants informed of new developments in research and to encourage ongoing dialogue between participants. Other recommendations included a webbased discussion board on the SIYM website, a special journal issue dedicated to projects initiated or developed at the Summer Institute, and inviting past participants back in subsequent years for further networking and professional development opportunities.

\section{Multi-dimensional Participation}

Mentoring programs may be operated by independent non-profit organisations; initiatives of schools, counties or other public entities; or partnerships between private and public institutions (DuBois \& Karcher 2005). Some mentoring programs use volunteers while others employ professional mentors. Programs can be school based, community based, or web based, and they can be short term or long term. Many organisations across the country support mentoring programs through a variety of resources. Nearly all of these types of programs were represented at the Summer Institute, and participants expressed appreciation of the diversity of viewpoints included in the discussions. One participant wrote: 'I 
liked having the variety of representatives present, including longtenured practitioners and relatively new ones, big agencies and small, practitioners and supporters, etc.'

\section{Clear Structure and Organisation}

Participants were generally satisfied with the organisation and structure of SIYM. Participants appreciated the three-hour blocks of time allotted for presentations, which allowed 'time to really examine the researcher's methods and findings'. Participants felt that the small group size and seminar structure facilitated inclusiveness, openness and critical evaluation of the material. One participant said: 'The intimate size of the group and interactive discussion format of the Institute created a stimulating and dynamic learning environment that encourages sustained dialogue among the participants'. Several participants suggested having more breaks, but the vast majority of comments related to the organisation and structure of the seminar, suggesting that participants found the experience powerful and rewarding: 'Having the researchers present their findings in front of everyone, allowing time throughout for questions and debate, helped us all better absorb the research, setting us up to more likely understand and implement the key findings when we returned to our workplace.'

\section{Integration into the Mission of Partnering Institutions}

Many participants explicitly described professional benefits from their experiences at SIYM, which can be divided into two categories. The first category might be called inspirational because of its personal and motivational nature. Several participants reported a renewed commitment to the mentoring field, saying that the Summer Institute was inspiring, invigorating and rejuvenating. One participant said: 'The enthusiasm and commitment to mentoring was infectious and motivating'. The second category involved the acquisition of skills and knowledge: 'I have been in the mentoring business for 27 years and this was one experience that truly expanded my knowledge base ... I learned more from the institute than from the last 15 conferences I have attended.' Other participants described very specific skills (e.g. how to set up a basic program evaluation) and knowledge (e.g. the importance of processes for ending mentoring relationships) that would directly inform and support their future work.

Several participants expressed concern that the momentum gained for program improvement at SIYM may be lost upon returning to their organisations. Potential obstacles included lack of resources for new initiatives, difficulty in integrating new ideas into established programs, resistance to change from employees and boards, and lack of time to fully communicate, plan and implement innovations. These barriers pose a threat to the potential for SIYM to become 'integrated into the mission of partnering organizations'. 


\section{Partnering Processes}

The concept of a partnering process as described by Torres and Schaffer (2000) is dynamic and multi-dimensional, incorporating the presence of relationships (which has already been described as a key component of participants' experiences), communication and work for positive change. Some participants spoke about components of the partnering process, but identified them as separate characteristics rather than as directly related parts. For example, one participant said that two-way communication between researchers and practitioners made SIYM a powerful professional development experience - but did not describe the formation of relationships or any specific positive change anticipated. Another spoke mostly of the potential for positive change: 'Both practitioners and researchers can offer new ideas and creative program ideas to each other - that was often the exciting part of our time together.' However, several participants conveyed the idea of a partnership by describing processes that combined these characteristics. One participant stated that, through SIYM, practitioners were able to help researchers translate what they had learned into effective practices. This simple statement demonstrates the intricate link between the relationships (developed during the Summer Institute), communication (practitioners helping researchers) and positive change (applying effective practices in the field). Another participant described the partnering process and the interplay of these three elements more explicitly: 'Having access to the researchers - hearing their findings, being able to discuss them fully, and being able to explore ways to improve our practices - was of extreme value.'

\section{Regular Evaluation}

Since its inception, SIYM has incorporated systems for participant feedback and ongoing evaluation of program effectiveness. The results of an initial evaluation of the 2007 Summer Institute and subsequent changes to the SIYM format were described earlier. Many other improvements to SIYM have been made in subsequent years.

There have also been several outgrowths from the initial SIYM. For example, in response to demand from local organisations, a half-day community symposium provides a summary of major themes and findings presented at SIYM to local practitioners. The success of SIYM also provided a foundation for the creation of the Center for Interdisciplinary Mentoring Research at Portland State University. The Center supports numerous events and initiatives promoting mentoring research and fostering connections with programs. In a comprehensive study of 19 university-community research partnerships sponsored by the Pew Partnership, Ferraiolo and Freedman (2002, p. 29) found that specialised campus-based research centres proved 'an effective and visible tool to connect university and community needs'. 


\section{SIGNIFICANT INNOVATIONS TO ESTABLISHED UNIVERSITY-COMMUNITY PARTNERSHIP MODELS}

Participant responses suggested that the Summer Institute on Youth Mentoring demonstrated several core characteristics that may be considered innovative in that they represent a departure from common university-community partnership models.

\section{Expanding the Idea of 'Community' in a Partnership}

Participants of the 2007 Summer Institute travelled to Portland from 14 states and two provinces in Canada. A review of records from the 2008, 2009 and 2010 Summer Institutes showed that participants, including research fellows, have now travelled from 30 states, four Canadian provinces and five foreign countries to participate. Most partnership efforts engage universities with communities that are in close physical proximity to the campuses. Some universities encourage students and faculty to make national and international connections (Hart \& Wolff 2006), but these partnerships are often still defined geographically. For example, one Tufts University effort serves under-resourced schools in Boston (Toomey 2007), while another Tufts partnership provides health resources in Tanzania (Kamuhabwa \& Lee 2009). Yet few universities have engaged larger, more conceptually defined groups, such as 'the mentoring community', as potential partners for university-community partnership projects. Even partnerships that seek to disseminate research findings to practitioners and other stakeholders rarely engage the intended audience directly, more often setting up online clearinghouses or distributing printed research summaries. While such partnerships attempt to bridge the gap between research and practice, evidence suggests that these dissemination methods are inadequate for creating changes in practice (Gira, Kessler \& Poertner 2004). SIYM, on the other hand, manages to reach an influential cohort of professionals from across the nation and world using strategies for dissemination, including interactive learning and the use of highly credible leaders in the field, who have shown promise in influencing the use of research findings in practice (Gira, Kessler, \& Poertner 2004).

Summer Institute participants described the benefit of sharing information with other participants from a wide range of locales. In some cases, representatives from rural programs that operate in geographic isolation experienced many partnership characteristics (e.g. personal relationships, shared vision, the partnering process) as encouraging and validating. Several participants also felt a new or renewed sense of community with other mentoring professionals, and expressed the belief that interpersonal relationships would help hold the community together. Engaging with others from diverse locations also inspired some participants to envision positive change that could be enacted through policy initiatives at the state and national levels. 
Using Short, Intensive Format to Achieve Long-term Goals Most university-community partnerships are intended to be ongoing collaborations in which partners meet regularly to plan and work together towards a common goal. Most partnership efforts require continuity and long-term commitment from all partners, but the SIYM has a different goal and a different approach. The SIYM itself lasts a week, while the relationships, communication, collaboration and change initiatives are intended to continue long after the SIYM has ended. In effect, the university plays 'matchmaker', bringing together dozens of participants and a handful of researchers to introduce them, help them to get to know each other, and encourage them to carry on meaningful and mutual relationships. The university's involvement with each individual participant may indeed be short and temporary (although a number of participants have returned for community events and symposia in subsequent years), but the engagement and commitment to the mentoring community, at least for some, appears set to last. In fact, a number of participants have described specific plans for engaging with research fellows, other researchers and each other in the coming months and years.

One drawback of the short-term nature of the SIYM was described by participants. Several practitioners felt that a more formal ongoing relationship with SIYM participants was necessary to keep the momentum going upon their return home. The 2007 SIYM included no formal process or forum for participants to keep in touch, except through an email list. One participant wrote: 'I feel like I have a cohort of support that I can draw on if needed', but added, 'I would like for that to be more ongoing and intentional ... maybe even just using the website or a group listserv that is focused on mentoring research issues'.

\section{Introducing an Inexpensive and Self-sustaining Approach}

Gilderbloom and Mullins (2005) describe two types of universitycommunity partnerships: 1) federally funded, top-down programs with a city-wide or regional focus, and 2) collaborative, locally funded, bottom-up approaches that focus on a single neighbourhood. While most partnerships have taken one of these forms, the SIYM introduced a relatively low-cost and sustainable approach that reached far beyond the typical geographic boundaries. Each stakeholder made financial or other resource investments in the program. Participants, or the organisations they work for, paid $\$ 725$ in tuition, plus travel expenses and other incidental costs. Although these expenses represent a significant investment on the part of participants and their organisations, the demand for learning opportunities such as SIYM will likely increase as foundations and government funders place ever greater expectations on programs to demonstrate outcomes. Furthermore, access to relevant research will grow in importance as funding becomes contingent on the use of evidence-based practices. Practitioner commitment to research-practice dialogue is likely to continue, as suggested by one SIYM participant's promise: 'And 
next time around, you can count on our organization for even more logistical and financial support in making it happen'. Since 2007, even as economic conditions disintegrated, interest and participation in the SIYM has increased steadily. Through 2010, 16 research fellows and four special guest speakers, as well as over 120 mentoring program leaders, have participated in the SIYM, with hundreds of others participating in the community events and symposia sponsored by the institute.

Beyond tuition revenue, two other sources of support contribute to the long-term viability of the SIYM. First, the PSU School of Social Work has an endowed professorship focused on youth mentoring research. This position provides dedicated time to direct the SIYM. The school also offers meeting spaces and other forms of tangible support. Second, the SIYM is supported by philanthropies that see value in a well-educated workforce for mentoring programs. The SIYM has been successful in securing funds from community foundations and individual donors. These resources are used to offer scholarships in the form of tuition reduction and to cover some general operating expenses.

\section{DISCUSSION}

The current study adds several important elements to our understanding of how successful university-community partnerships operate, and how they can adopt or develop sustainable practices over the long-term. First, the findings lend support for the list of successful partnership characteristics proposed at the Wingspread conference and reported by Torres and Schaffer (2000). The relative lack of empirical studies comparing partnership efforts makes it difficult to confirm whether factors identified by one study are pertinent beyond the (usual) single case examined. This study helps move the universitycommunity partnership field one step closer to establishing a reliable framework that practitioners and researchers can use as a foundation for evaluating and strengthening existing partnerships or establishing new ones. While the current study complements and extends our knowledge about universitycommunity partnerships, the cross-sectional design provides only a snapshot of participants' attitudes following the event, and does not offer any indication of the longer-term impacts that the SIYM may have had on practitioners, researchers and mentoring programs themselves. We recommend that future research be directed towards longitudinal evaluation of partnerships at both individual and agency levels. Partnership researchers can also use emerging knowledge about the characteristics of successful partnerships to explore how these characteristics are related to one another. In other words, studies like this may help set the stage for conceptualising and testing dynamic models of partnership processes, moving beyond simple lists to understanding how the interplay of structures and relationships contribute to the development and perpetuation of effective partnership initiatives. 
The Summer Institute also demonstrated that dissemination of research findings and discussion on the implications of research can be successfully facilitated in person and especially through building interpersonal relationships. Not only are the typical clearinghouse and conference approaches ineffective strategies for putting research findings to use (Gira, Kessler, \& Poertner 2004), they largely neglect the important contribution that practitioners can make to the research-to-practice (and practiceto-research) conversation. In contrast, SIYM facilitated meaningful dialogue and relationships designed to keep the communication going beyond the seminar week. Considering that the research literature and practice knowledge are continually expanding, SIYM has introduced a format that could help move away from passive modes of dissemination to utilise active processes of implementation and integration of important research findings.

The SIYM model also demonstrated the potential for university-community partnerships to raise the standards for professional development. Several participants said that the SIYM was the best professional development experience of their careers. SIYM combined the research of academic conferences with the intensive and interactive nature of professional training to offer a model that participants found rewarding, inspiring and, in some cases, transformative. A review of effective professional development practices in schools found that successful programs shifted their focus 'from isolated learning and the occasional workshop to ... collaborative reflection and joint action' (WestEd 2000, p. 11). One participant described the importance of collaborative reflection while discussing the Summer Institute, saying: 'I believe [practitioners and researchers] need each other sort of like holding up a mirror to let each other know what things look like from a different perspective'. The findings of the current study also showed that the SIYM successfully addressed what Smith and Gillespie (2007) found were several major obstacles to professional development in education, including time constraints, lack of face-to-face interaction, and mismatch of goals, suggesting that the innovative SIYM model could be applied more broadly to bring practitioners and researchers together to make better use of research and practice knowledge.

Finally, SIYM offers a low-cost, sustainable model of university-community collaboration that can have large-scale and potentially long-term impacts. Many partnership models require substantial financial resources. Bloomgarden and colleagues (2006) describe the challenge of securing matching funds from university and community partners in order to qualify for federal grants. Holland (2003, p. 4) contends that pursuit of external funding from various sources can lead to 'the trap of episodic attention to individual grants and projects, which tends to create superficial and temporary relationships'. The Summer Institute has from the beginning taken an entrepreneurial approach and relied on a balanced combination of funding from 1) tuition payments 
from participants, 2) university support in the form of faculty time dedicated to directorship of SIYM, and 3) small foundation grants for community events and other expenses. The relatively low cost of the event combined with significant contributions from stakeholders may be a formula that attracts increasing attention as the economy continues to struggle. While this sustainable model may impose certain logistical limitations on SIYM, the event has enjoyed consistent growth and expanded reach since its inaugural year.

There are several limitations to the current study that should be considered. First, the combined return rate for questionnaires was 55 per cent, meaning that data analysis was based on responses from just over half of SIYM attendees. There is no way to tell how the participation of non-responders would have changed the results. It is possible that participants who had a positive experience were more likely to fill out and return questionnaires. Second, while various measures were taken to ensure the trustworthiness of the study's results, the authors' professional involvement with the Summer Institute may have introduced an element of bias into the data analysis and the interpretation of findings. Finally, the partnership models described in this study are largely untested and their long-term impacts are unknown, so further research is needed before conclusions can be drawn about the value of one partnership model versus another. Despite these limitations, the findings of the current study tell a compelling story of an innovative university-community partnership that may offer other organisations and institutions a framework for establishing their own successful collaborative efforts.

\section{ACKNOWLEDGEMENTS}

This work was made possible through the support of the Center for Academic Excellence at Portland State University. The authors sincerely thank the mentoring researchers and professionals who participated in this study.

\section{REFERENCES}

Addis, M 2002, 'Methods for disseminating research products and increasing evidence based practice: Promises, obstacles, and future directions', Clinical Psychology: Science and Practice, vol. 9, no. 4, pp. 381-92.

Baum, H 2000, 'Fantasies and realities in university-community partnerships', Journal of Planning Education and Research, vol. 20, no. 2, pp. 234-46.

Bloomgarden, A, Bombardier, M, Breitbart, M, Nagel, K \& Smith, P 2006, 'The Holyoke Planning Network: Building a sustainable college/ community partnership in a metropolitan setting', in R Forrant \& L Silka (eds), Inside and out: Universities and education for sustainable development, Baywood, NY.

Butterfield, A \& Soska, T 2004, 'University-community partnerships: An introduction', Journal of Community Practice, vol. 12, nos 3 \& 4, pp. 1-11. 
New directions in civic engagement: University avenue meets main street, Pew Partnership for Civic Change/University of Richmond, Richmond, VA.

Cherry, D \& Shefner, J 2004, 'Addressing barriers to university-community collaboration: Organizing by experts or organizing the experts?', Journal of Community Practice, vol. 12, nos 3 \& 4, pp. 219-33.

Cox, D 2000, 'Developing a framework for understanding universitycommunity partnerships', Cityscape: A Journal of Policy Development and Research, vol. 5, no. 1, pp. 9-25.

DuBois, D \& Karcher, M 2005, 'Youth mentoring: Theory, research, and practice', in D DuBois \& M Karcher (eds), Handbook of youth mentoring, Sage Publications, Thousand Oaks, CA.

Ferraiolo, K \& Freedman, P 2002, 'Wanted: Solutions for America - Preliminary research collaboration findings', report presented at the Conference on Building University-Community Research Partnerships, Charlottesville, Virginia, 16-17 October 2002.

Gilderbloom, J \& Mullins, R 2005, Promise and betrayal: Universities and the battle for sustainable urban neighborhoods, State University of New York Press, Albany, NY.

Gira, E, Kessler, M \& Poertner, J 2004, 'Influencing social workers to use research evidence in practice: Lessons from medicine and the allied health professions', Research on Social Work Practice, vol. 14, no. 2, pp. 68-79.

Hart, A \& Wolff, D 2006, 'Developing local "communities of practice" through local community-university partnerships', Planning, Practice \& Research, vol. 21, no. 1, pp. 121-38.

Hatch, A 2002, Doing qualitative research in educational settings, State University of New York Press, Albany, NY.

Holland, B 2003, 'Community-university partnerships: Translating evidence into action', in B Holland, S Gelmon, L Green, E Greene-Moton \& T Stanton (co-chairs), Community-university partnerships: What do we know? Prepared for discussion at a National Symposium, CommunityUniversity Partnerships: Translating Evidence into Action, jointly sponsored by Community-Campus Partnerships for Health and HUD's Office of University Partnerships, San Diego, California, 26 April 2003.

Jones K \& Keller, T 2009, Establishing true community-university partnerships: The Summer Institute on Youth Mentoring, report presented at the International Partnership Institute, 18-19 May 2009, Portland, OR.

Kamuhabwa, A \& Lee, M 2009, 'Bridging the human resources for health (HRH) gap in Tanzania: A model for mutual success', presented by Muhimbili University of Health and Allied Sciences (MUHAS), Tanzania, and Tufts University, USA, Accra, Ghana, 27 August 2009, viewed 10 July 2010, www.hedprogram.org/LinkClick.aspx?fileticket=9yxGQKbKSfo\%3D $\underline{\text { \&tabid }=225}$.

Karcher, M 2008, Book review of G Clary \& J Rhodes (eds), Mobilizing adults for positive youth development: Strategies for closing the gap between beliefs and behaviors, Journal of Youth and Adolescence, vol. 37, no. 4, pp. $475-80$.

Lane, J, Turner, S \& Flores, C 2004, 'Researcher-practitioner collaboration in community corrections: Overcoming hurdles for successful partnerships', Criminal Justice Review, vol. 29, no. 1, pp. 97-114. 
Lietz, C, Langer, C \& Furman, R 2006, 'Establishing trustworthiness in social work research: Implications from a study regarding spirituality', Qualitative Social Work, vol. 5, no. 4, pp. 441-58.

Mai, R, Kramer, T \& Luebbert, C 2005, 'Learning through partnering: Lessons for organizational and community renewal', Journal of Community Practice, vol. 13, no. 2, pp. 107-22.

Saltmarsh, J, Hartley, M \& Clayton, P 2009, Democratic engagement white paper, New England Resource Center for Higher Education, Boston, MA.

Schumaker, A, Reed, B \& Woods, S 2000, 'Collaborative models for metropolitan university outreach: The Omaha experience', Cityscape: A Journal of Policy Development and Research, vol. 5, no. 1, pp. 197-207.

Sherrod, L 1999, 'Giving child development knowledge away: Using university-community partnerships to disseminate research on children, youth and families', Applied Developmental Science, vol. 3, no. 4, pp. 228-34.

Smith, C \& Gillespie, M 2007, 'Research on professional development and teacher change: Implications for adult basic education', Review of Adult Learning and Literacy, vol. 7, p. 1.

Strauss, A \& Corbin, J 1990, Basics of qualitative research: Grounded theory procedures and techniques, Sage Publications, Newbury Park, CA.

Toomey, M 2007, Essential literacy partnerships at the South Lawrence East Elementary School, Coalition of Essential Schools, viewed 10 July 2010, www.essentialschools.org/resources/371.

Torres, J \& Schaffer, J 2000, Benchmarks for campus/community partnerships, Campus Compact, Providence, RI.

US Department of Housing and Urban Development 2010, Collaborating for change: Partnerships to transform local communities, HUD Office of Policy Development and Research, Washington, DC, viewed 12 August 2010, www.oup.org/files/pubs/collaboratingforchange.pdf.

Walker, G 2007, Mentoring, policy, and politics, Public/Private Ventures, viewed 8 October 2010, www.ppv.org.

WestEd 2000, Teachers who learn, kids who achieve: A look at schools with model professional development, WestEd, San Francisco, CA, viewed 10 June 2010, www.wested.org/online pubs/teachers who learn/TeachLearn.pdf.

Wilson, D 2004, 'Key features of successful university-community partnerships', in K Ferraiolo (ed.), New directions in civic engagement: University avenue meets main street, Pew Partnership for Civic Change/ University of Richmond, Richmond, VA. 